\title{
A CASE OF SJOGREN'S SYNDROME PRESENTING AS QUADRIPARESIS
}

\section{Poongavanam Paranthaman1, Kiran Josy Kanjamala², Jayakrishnan Jeyakumar ${ }^{3}$, Thenrajan Balaji ${ }^{4}$}

1 Professor, Department of General Medicine, Government Royapettah Hospital, Kilpauk Medical College. 2Post Graduate, Department of General Medicine, Government Royapettah Hospital, Kilpauk Medical College. ${ }_{3}^{3}$ Assistant Professor, Department of General Medicine, Government Royapettah Hospital, Kilpauk Medical College. ${ }_{4}^{4}$ Assistant Professor, Department of General Medicine, Government Royapettah Hospital, Kilpauk Medical College.

\section{ABSTRACT}

Hypokalaemia presenting as quadriplegia is common, but association with renal tubular acidosis and Sjogren's syndrome is a rare entity. We present a case of 35-year-old female admitted with acute onset quadriplegia with dysphagia for solids and parotid enlargement with normal anion gap metabolic acidosis. CT-abdomen showed bilateral renal stone disease and high positivity of autoantibody (SS-A)/anti Ro and histopathology of minor salivary gland showed lymphocytic infiltrations suggestive of immune mediated destruction of salivary gland meeting the American-European Consensus Classification Criteria of primary Sjogren's syndrome. Patient was managed appropriately with correction of hypokalaemia and acidosis and recovered completely three days after admission.

\section{KEYWORDS}

Sjogren's Syndrome, Quadriparesis, Distal Renal Tubular Acidosis.

HOW TO CITE THIS ARTICLE: Paranthaman P, Kanjamala KJ, Jeyakumar J, et al. A case of Sjogren's syndrome presenting as quadriparesis. J. Evolution Med. Dent. Sci. 2016;5(52):3465-3467, DOI: 10.14260/jemds/2016/799

\section{INTRODUCTION}

Primary Sjogren's syndrome occurs from $0.1-3.0 \%$ in general population. The disease is more common for women (Female/Male=9:1). The major clinical renal manifestations of patients with Sjogren's syndrome usually relate to tubulointerstitial involvement of the kidneys with tubular defects such as a distal RTA, hypercalciuria, and less frequently proximal tubular defects. ${ }^{1}$ A frank distal RTA was found in 5\% of patients with Sjogren's syndrome. We herein describe a case of Sjogren's syndrome presenting as quadriparesis.

\section{CASE REPORT}

Thirty five years old female, P3L2A0 presented with history of acute onset of weakness of bilateral upper and lower limb since 2 days. History of noted swelling just below the left ear 2 months back and difficulty in swallowing solid food for past 6 months.

No history of difficulty in breathing, sensory impairment, bowel or bladder disturbances. No history of high carbohydrate diet intake or unusual physical exertion history of similar episodes of acute onset weakness of limbs about 2 episodes in the past 1 year, treated and completely reversed with potassium supplementation.

O/E - Patient is moderately built, Dyspnoeic and tachypnoeic, not cyanosed.

Not anaemic, icteric, clubbing, pedal oedema, generalized lymphadenopathy, dental caries in the incisor teeth (which is an unusual site).

Financial or Other, Competing Interest: None.

Submission 14-05-2016, Peer Review 09-06-2016,

Acceptance 13-06-2016, Published 30-06-2016.

Corresponding Author:

Dr. P. Paranthaman,

\#26/5, Moorthy Nagar,

Vilivakkam,

Chennai-49.

E-mail: paranthaman1964@rediffmail.com

DOI: $10.14260 /$ jemds $/ 2016 / 799$

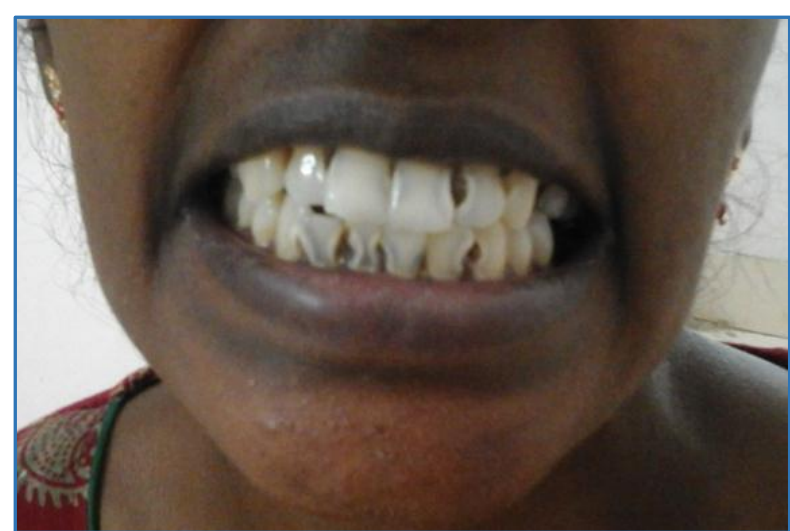

Fig. 1: Local Examination-Dental Caries in the Incisor Teeth (Uncommon Site) due to Decreased Salivation

Pulse 84/minute, regular and no special character, BP: 110/70 mmHg, RR: 42 per minute, regular, Temperature 98.6 F. Systemic Examination CNS, Higher mental functions and cranial nerves-normal.

\section{Motor System Examination}

Power $4 / 5$ in bilateral upper limbs and $3 / 5$ in bilateral lower limbs. Sensory, autonomic, cerebellum and spine, cranium and other system examination within normal limits.

\section{Investigations}

Hb-11 gm/dL with normal WBC and platelet count. Fasting blood sugar- $102 \mathrm{mg} / \mathrm{dL}, \mathrm{BUN}-11 \mathrm{mg} / \mathrm{dL}$, serum creatinine$0.7 \mathrm{mg} / \mathrm{dL}$. ESR-60 mm/hour. Serum sodium-140, potassium-1.8, chloride-120, bicarbonate-11 $\mathrm{mEq} / \mathrm{L}$ respectively, Serum calcium-8.6, magnesium-1.8 (mEq/litre).

\section{Anion Gap}

10.8. (10-12), spot urine $\mathrm{k}+44(20-40)$.

\begin{tabular}{|c|c|c|c|c|c|c|c|}
\hline Date & $\mathbf{p H}$ & $\mathbf{P C O}_{2}$ & $\mathbf{P O}_{2}$ & $\mathbf{H C O}_{3}-$ & $\mathbf{S O}_{2}$ & $\mathbf{N a +}$ & $\mathbf{K +}$ \\
\hline Day 1 & 7.25 & 24 & 99 & 11 & 99 & 140 & 1.8 \\
\hline Day 3 & 7.35 & 34 & 99 & 16.4 & 99 & 142 & 4 \\
\hline \multicolumn{7}{|c|}{ Arterial Blood Gas Analysis } \\
\hline
\end{tabular}




\section{Normal Anion Gap Metabolic Acidosis}

Urine pH:7, plasma osmolality $=289.594$ (270-290) urine osmolality $=685 \mathrm{mosm} /$ litre $(500-800)$ TTKG (Trans-tubular potassium gradient) $=32$ suggests renal loss of potassium Normal value of TTKG 8-9; in hyperkalaemia it is greater than 11 and in hypokalaemia it will come down to 3.

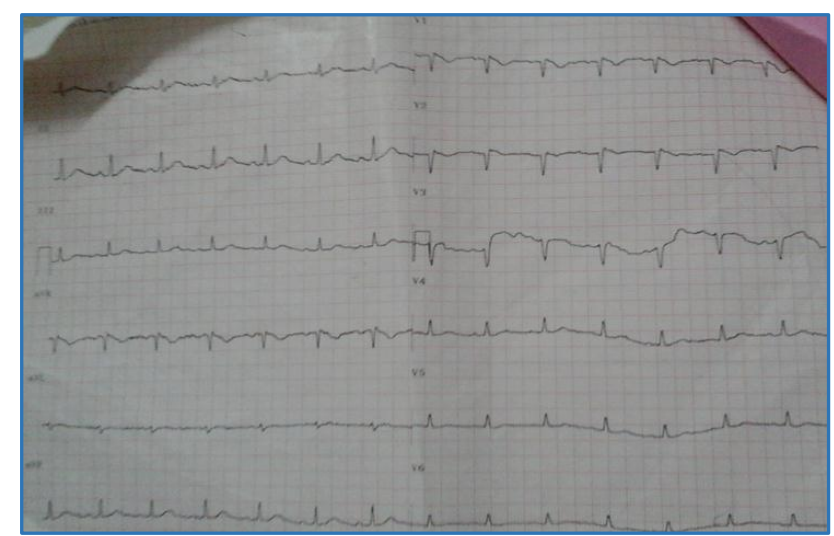

Fig. 2: ECG-Small Amplitude 'T' Waves with Prominent $U$ Waves Suggestive of Hypokalaemia

As the patient had urinary loss of potassium and normal anion gap metabolic acidosis, the patient was diagnosed to have distal renal tubular acidosis and the hypokalaemia causing quadriparesis. As patient had history suggestive of Sjogren's syndrome due to dysphagia to solids and swelling below the left ear, immunological workup was done.

Rheumatoid Factor RF-negative, Anti-CCCP-negative, Anti-dsDNA-negative, ANA + (2.85) speckled pattern, C3, C4 levels in normal range, Anti Ro/ SSA- High positive, Anti La/SSB -negative, CRP- negative, CPK, LDH- normal, Thyroid function test-normal, Schirmer's test- positive (Less than 5 $\mathrm{mm}$ in 5 minutes).

HIV, HBsAg, Anti HCV- non-reactive.

Minor salivary gland biopsy from lower lip shows focal lymphoid infiltration consistent with Sjogren's syndrome. USG- within normal limits.

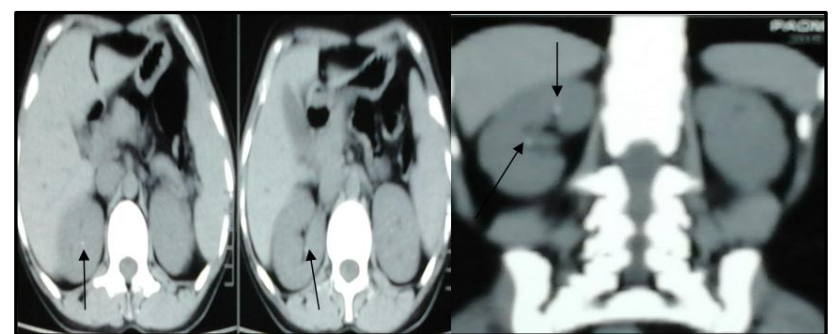

Fig. 3: CT Abdomen-b/l Kidneys-Multiple 3-4 mm Calculi (due to Tubulointerstitial Involvement of the Kidney and Hypercalciuria in Sjogren's Syndrome)

\section{Final Diagnosis}

Hypokalaemia induced quadriparesis due to distal renal tubular acidosis secondary to autoimmune disease Sjogren's Syndrome.

The diagnosis of primary Sjogren's syndrome was made based on the American-European Consensus Classification Criteria as follows.

The classification criteria for Sjogren's Syndrome (SS) currently used by clinicians and researchers around the world is the American-European Consensus Classification Criteria.

\section{Ocular Symptoms (At least one)}

- Dry eyes $>3$ months?

- Foreign body sensation in the eyes?

- Use of artificial tears $>3 x$ per day?

\section{Oral Symptoms (At least one)}

- $\quad$ Dry mouth $>3$ months?

- Recurrent or persistently swollen salivary glands?

- Need liquids to swallow dry foods?

\section{Ocular Signs (At least one)}

- Schirmer's test, (Without anaesthesia) $\leq 5 \mathrm{~mm} / 5$ minutes.

- $\quad$ Positive vital dye staining (Van Bijsterveld $\geq 4$ ).

\section{Histopathology}

- Lip biopsy showing focal lymphocytic sialadenitis (Focus score $\geq 1$ per $4 \mathrm{~mm}^{2}$ ). ${ }^{2}$

\section{Oral Signs (At least one)}

- Unstimulated whole salivary flow $(\leq 1.5 \mathrm{~mL}$ in 15 minutes).

- Abnormal parotid sialography. ${ }^{3}$

- Abnormal salivary scintigraphy. ${ }^{3}$

\section{Autoantibodies (At least one)}

- Anti-SSA (Ro) or Anti-SSB (La).

\section{For a Primary Sjogren's Diagnosis}

a. Any 4 of the 6 criteria must include either item IV (Histopathology) or VI (Autoantibodies), b. Any 3 of the 4 objective criteria (III, IV, V, VI).

\section{For a Secondary Sjogren's Diagnosis}

In patients with another well-defined major connective tissue disease, the presence of one symptom (I or II) plus 2 of the 3 objective criteria (III, IV and V) is indicative of secondary SS.

\section{Exclusion Criteria}

- Past head and neck radiation treatment.

- Hepatitis C infection.

- Acquired Immunodeficiency Syndrome (AIDS).

- Pre-existing lymphoma.

- Sarcoidosis.

- Graft versus host disease.

- Current use of anticholinergic drugs.

Our patient presented with dryness of mouth with positive Schirmer's test, Anti Ro (SS-A) high positive and biopsy of minor salivary gland showing focal lymphoid infiltration; three of the four objective criteria (III, IV, VI) consistent with Sjogren's syndrome.

Hence we report this case to highlight the fact that patients presenting with hypokalaemic periodic paralysis with metabolic acidosis can be due to Renal Tubular Acidosis with primary Sjogren's syndrome.

\section{Management}

Patient was managed with intravenous and oral potassium. Metabolic acidosis was corrected with intravenous infusion of bicarbonate. Hypokalaemia got corrected over a period of 3 days with gradual and complete recovery of limb weakness. 
Patient was discharged on sodium bicarbonate tablets and syrup KCL.

\section{DISCUSSION}

Sjogren's Syndrome (SS) is a chronic autoimmune disease in which the body's white blood cells destroy the moisture producing glands of the body. It can cause debilitating, profound fatigue, chronic pain and other problems that can lead to disability. SS attacks the exocrine glands, specifically the salivary and lacrimal glands that produce saliva and tears respectively. The immune-mediated attack on the salivary and lacrimal glands leads to the development of xerostomia (Dry mouth) and keratoconjunctivitis sicca (Dry eyes), which takes place in association with lymphocytic infiltration of the glands. That inflammatory process eventually severely damages or destroys the glands.

Renal Tubular Acidosis (RTA) develops in a large population of patients with Sjogren's Syndrome (SS), but most of the subjects are asymptomatic, but in our case the patient presented with quadriparesis with xerostomia and parotid enlargement that prompted us to suspect Sjogren's syndrome.

Patients with distal RTA commonly present with symptoms of renal stones, but the first abnormality might be the symptoms of hypokalaemia. Thirty to $40 \%$ of patients with SS have symptomatic or asymptomatic renal involvement. However, severe symptomatic hypokalaemia is rare.

\section{CONCLUSION}

Although hypokalaemia presenting as quadriplegia is common, association with renal tubular acidosis due to Sjogren's syndrome is rare. Our patient presented with dryness of mouth with difficulty in swallowing with parotid enlargement, which prompted us to think of primary Sjogren's syndrome which is an uncommon association. Immunological workup and the histopathology of minor salivary gland was consistent with primary Sjogren's syndrome, therefore the complete diagnosis helped us to manage this case appropriately.

\section{REFERENCES}

1. Toosi TD, Naderi N, Movassaghi S, et al. Secondary Sjogren's syndrome presenting with hypokalaemic periodic paralysis. Oxf Med Case Reports 2014;2014(8):135-7.

2. Palkar AV, Pillai S, Rajadhyaksha GC. Hypokalaemic quadriparesis in Sjogren syndrome. Indian Journal of Nephrology 2011;21(3):191-3.

3. Christensen KS. Hypokalaemic paralysis in Sjogren's syndrome secondary to renal tubular acidosis. Scand J Rheumatology 1985;14(1):58-60. 